\title{
Effects of Blood Heavy Metal Concentration in School Children on Allergic Disease
}

\author{
Hye-Seon Choi ${ }^{1}$, Hye-Young $\mathrm{Ahn}^{2 *}$, Jin-Ju Woo ${ }^{3}$ \\ ${ }^{1}$ Dept. of Nursing, Woosuk University \\ ${ }^{2}$ Dept. of Nursing, Eulji University \\ ${ }^{3}$ Dept. of Nursing, Gyeongbuk College of Health \\ 2*(Corresponding Author) ahanaya@eulji.ac.kr
}

\begin{abstract}
The aim of the study is to examine the influence of blood heavy metal concentration on allergic disease in children. The numbers of subjects were 1,065 from The Sixth Korea National Health and Nutrition Examination Survey (KNHANES VI-1) 2013. SPSS 24 was used for statistical analysis with complex sample survey modules and commands. As a result, the geometric mean concentrations of lead, mercury and cadmium in the blood were $1.25 \pm 0.03 \mu \mathrm{g}$ $/ d L, 1.95 \pm 0.08 \mu \mathrm{g} / \mathrm{L}$ and $0.35 \pm 0.03 \mu \mathrm{g} / \mathrm{L}$. The children's blood mercury levels were related to the Allergic rhinitis $(p=.040)$. More research is needed to investigate this relationship.
\end{abstract}

Keywords: Atopic Dermatitis, Allergic Rhinitis, Asthma, Health Surveys, Heavy Metal

\section{Introduction}

These days, when environmental pollution becomes serious, it increases the risk of exposure to heavy metal as well as to fine dust. Heavy metal, once absorbed into the body, is combined with biomaterials, is hardly resolved, is accumulated in the body, and exerts several negative effects. In the life cycle, particularly, it is more hazardous in childhood and in adolescence[1].The representative effects of exposure to heavy metal on children's health include delayed growth and development [2], asthma [3], learning disorder [4], emotional disorder, and sleep disorder [1][5]. Of these, it is necessary to focus on heavy metal and allergic diseases, which are on the constant increase [5][6]. It is necessary to pay greater attention to allergic diseases in childhood and in adolescence, which are on the annual increase in South Korea [7].

This study aimed to use the data from the Korea National Health and Nutrition Examination Survey (KNHNES) that could represent the whole population of South Korea to analyze the effects of the heavy metal concentration in blood on allergic diseases for South Korean children. ${ }^{1}$

\section{Methods}

\subsection{Study design}

This is descriptive research that made the secondary analysis of the data from the sixth KNHNES in the first year (2013) to determine the effects of the heavy metal concentration in blood on allergic diseases for children.

Article history:

Received (January 15, 2018), Review Result (February 19, 2018), Accepted (April 8, 2018) 


\subsection{Subject and data collection}

This study used the data from the sixth KNHNES in the first year (2013)[8]. 1,065 children participating in every test for heavy metal (lead, mercury, and cadmium) among the items in KNHNES were finally analyzed.

\subsection{Instrument}

2.3.1 General characteristics: The data concerning gender, age, income, quartile (household), 16 cities, and housing type among the items in KNHNES were used to analyze the general characteristics [8].

2.3.2 Allergic disease: Of the items in the survey on health, those regarding doctors' diagnosis status and time for asthma, atopic dermatitis, and allergic rhinitis were analyzed for allergic diseases [8].

2.3.3 Heavy metal concentration in blood: The concentration of lead and cadmium in blood was measured by using PerkinElmerAAnalyst600 (PerkinElmer/Finland) to perform graphite furnace atomic absorption spectroscopy (GFAAS). The concentration of mercury in blood was measured by using PerkinElmer ICP-MS (PerkinElmer/USA) to perform inductively coupled plasma-mass spectroscopy (ICP/MS) [8]. The recommended concentration of heavy metal in blood was based on the CDC criteria [9] for lead and cadmium and on the HBMI criteria [10] for mercury.

\subsection{Data analysis}

All the data were analyzed using an SPSS 24 program with two-sided test at the $\alpha=.05$ significance level. The data drawn by complex stratified sampling were statistically analyzed by applying weight, stratified variables, and cluster variables. As for statistical methods, complex sampling frequency and percentage were used to analyze allergic diseases and complex sampling descriptive statistics (mean and standard deviation) was used to analyze the heavy metal concentration in blood. Complex sampling logistic regression analysis was used to analyze the effects of the heavy metal concentration in blood on allergic diseases.

\section{Results}

\subsection{Subjects' general characteristics}

$52.2 \%$ of the respondents were male, and $47.8 \%$ female; $52.9 \%$ were aged $7-12$ years (elementary school children), 30.4\% 13-15 years (middle school students), and 16.7\% 16-18 years (high school students). For economic status, $61.5 \%$ were at the middle level, $27.3 \%$ at the high level, and $11.3 \%$ at the low level. $48.9 \%$ resided in the metropolitan area; $58.4 \%$ lived in apartments, and $41.6 \%$ in general houses Table 1. 
Table 1. General characteristics of subjects $(\mathrm{N}=1,065)$

\begin{tabular}{|c|c|c|c|}
\hline Characteristics & Categories & Weighted \% & $\mathbf{n}$ \\
\hline \multirow{2}{*}{ Gender } & Male & $52.2 \%$ & 563 \\
\hline & Female & $47.8 \%$ & 502 \\
\hline \multirow{3}{*}{$\begin{array}{l}\text { Age } \\
\text { (year) }\end{array}$} & $\begin{array}{l}\text { 7-12 (elementary school } \\
\text { students) }\end{array}$ & $52.9 \%$ & 641 \\
\hline & 13-15 (middle school students) & $30.4 \%$ & 291 \\
\hline & 16-18 (high school students) & $16.7 \%$ & 133 \\
\hline \multirow{3}{*}{$\begin{array}{l}\text { Economic } \\
\text { status* }\end{array}$} & Low & $11.3 \%$ & 116 \\
\hline & Middle & $61.5 \%$ & 632 \\
\hline & High & $27.3 \%$ & 309 \\
\hline \multirow{5}{*}{ Residentialarea } & Capital area & $48.9 \%$ & 553 \\
\hline & Chungcheong area & $11.2 \%$ & 109 \\
\hline & $\begin{array}{l}\text { Daegu } \cdot \text { Gyeongbuk } \cdot \text { Gangwon } \\
\text { area }\end{array}$ & $12.2 \%$ & 145 \\
\hline & $\begin{array}{l}\text { Busan · Ulsan · Gyeongnam } \\
\text { area }\end{array}$ & $15.4 \%$ & 114 \\
\hline & Honam · Jeju area & $12.2 \%$ & 144 \\
\hline \multirow{2}{*}{ Housing type } & House & $41.6 \%$ & 403 \\
\hline & Condominium & $58.4 \%$ & 662 \\
\hline
\end{tabular}

*Exclude no reply

\subsection{Allergic disease}

As for allergic diseases, $6.2 \%$ of the children were diagnosed with asthma by doctors, $17.7 \%$ with atopic dermatitis, and $24.7 \%$ with allergic rhinitis Table 2.

Table 2. Diagnosis of allergic disease

\begin{tabular}{|c|c|c|}
\hline Variables & Categories & Weighted \% \\
\hline \multirow{3}{*}{ Asthma } & No & $93.7 \%$ \\
\cline { 2 - 3 } & Yes & $6.2 \%$ \\
\cline { 2 - 3 } & None & $0.1 \%$ \\
Atopic dermatitis & No & $82.2 \%$ \\
\cline { 2 - 3 } & Yes & $17.7 \%$ \\
\hline
\end{tabular}




\begin{tabular}{|c|c|c|}
\cline { 2 - 3 } & None & $0.1 \%$ \\
\hline \multirow{4}{*}{ Allergic rhinitis } & No & $75.2 \%$ \\
\cline { 2 - 3 } & Yes & $24.7 \%$ \\
\cline { 2 - 3 } & None & $0.1 \%$ \\
\hline
\end{tabular}

\subsection{Heavy metal concentration in blood}

The geometric average of concentration in blood was $1.25 \pm 0.03 \mu \mathrm{g} / \mathrm{dL}$ for lead, $1.95 \pm 0.08$ $\mu \mathrm{g} / \mathrm{L}$ for mercury, and $0.35 \pm 0.03 \mu \mathrm{g} / \mathrm{L}$ for cadmiumTable 3 .

Table 3. Blood heavy metal concentration

\begin{tabular}{|c|c|c|}
\hline Variables & GM & SD \\
\hline $\operatorname{Lead}(\mu \mathrm{g} / \mathrm{dL})$ & 1.25 & 0.03 \\
\hline Mercury $(\mu \mathrm{g} / \mathrm{L})$ & 1.95 & 0.08 \\
\hline Cadmium $(\mu \mathrm{g} / \mathrm{L})$ & 0.35 & 0.03 \\
\hline
\end{tabular}

Note. GM: Geometric Mean, SD: Standard deviation

\subsection{Effects of heavy metal concentration in blood on allergic disease}

A $0.1 \mu \mathrm{g} / \mathrm{L}$ increase in the concentration of mercury in blood led to a significant increase by 1.31 times in the risk of allergic rhinitis $(\mathrm{p}=.040)$ Table 4.

Table 4. Blood heavy metal concentration influencing on allergic disease

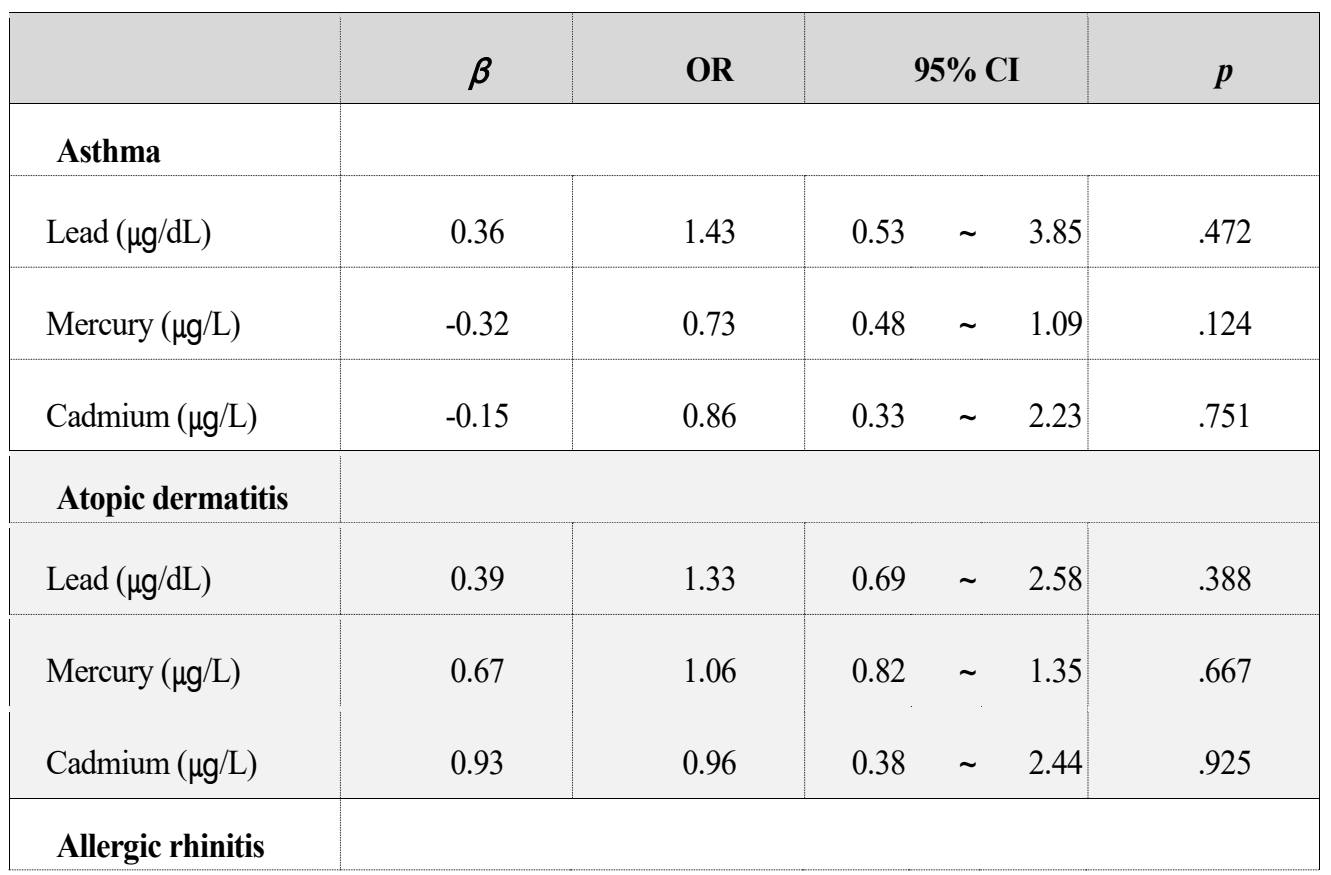




\begin{tabular}{|l|c|c|cc|c|}
\hline $\operatorname{Lead}(\mu \mathrm{g} / \mathrm{dL})$ & 0.10 & 1.10 & $0.56 \sim 2.18$ & .783 \\
\hline Mercury $(\mu \mathrm{g} / \mathrm{L})$ & 0.27 & 1.31 & $1.01 \sim 1.70$ & .040 \\
\hline Cadmium $(\mu \mathrm{g} / \mathrm{L})$ & -0.41 & 0.67 & $0.30 \sim 1.48$ & .315 \\
\hline
\end{tabular}

\section{Conclusion}

This study made the secondary analysis of the data from KNHNES to determine the effects of the heavy metal concentration in blood on allergic diseases for children. The concentration of both lead and mercury in blood $-1.25 \pm 0.03 \mu \mathrm{g} / \mathrm{dL}$ and $1.95 \pm 0.08 \mu \mathrm{g} / \mathrm{L}$, respectively-was higher than the international one: NHANES $0.84 \mu \mathrm{g} / \mathrm{dL}$ and CHMS $0.80 \mu \mathrm{g} / \mathrm{dL}[9,11]$ and NHANES $0.54 \mu \mathrm{g} / \mathrm{L}[9]$, respectively.

In contrast, the concentration of cadmium in blood- $0.35 \pm 0.03 \mu \mathrm{g} / \mathrm{L}-$ was similar to the international one: NHANES $0.33 \mu \mathrm{g} / \mathrm{L}$ [9]. Interestingly, the concentration of mercury in blood affected allergic rhinitis for children in this study: an $0.1 \mu \mathrm{g} / \mathrm{L}$ increase in the concentration of mercury in blood led to a significant increase by 1.31 times in the risk of allergic rhinitis $(\mathrm{p}=.040)$.

These results demonstrate that the concentration of heavy metal in blood affects allergic diseases for children. Unfortunately, this study used the data from KNHNES and failed to reflect diverse factors related to allergic diseases and heavy metal exposure, such as children's diet and internal and external environmental factors (parents and surrounding environment). So analytic-epidemiologic research should be conducted to identify the factors related to allergic diseases, taking the properties of each heavy metal into account.

\section{References}

[1] C. Edelman, C. L. Mandle, and E. C. Kudzma, Health Promotion throughout the Life Span, 8th ed. Elsevier, Amsterdam, (2014)

[2] Y. M. Hsueh, C. Y. Lee, S. N. Chien, W. J. Chen, H. S. Shiue, S. R. Huang, M. I. Lin, S. C. Mu, and R. L. Hsieh, Association of Blood Heavy Metals with Developmental Delays and Health Status in Children. Scientific Reports. 7, 43608, (2017)

[3] https://www.niehs.nih.gov/health/topics/conditions/asthma/, Jan 22 (2018).

[4] S. Wang and J. Zhang, Blood Lead Levels in Children, China. Environmental Research. 101, 3, (2006)

[5] C. G. Sears and K. M. Zierold, Health of Children Living Near Coal Ash. Global Pediatric Health. 4, (2017)

[6] Y. Miyake, K. Tanaka, A. Yasutake, S. Sasaki, and Y. Hirota, Lack of Association of Mercury with Risk of Wheeze and Eczema in Japanese Children: the Osaka Maternal and Child Health Study. Environmental Research. 111, 8, (2011)

[7] Y. H. Lee, J. H. Choi, M. R. Park, J. H. Kim, W. K. Kim, Y. M. Park, S. Y. Lee, M. Y. Han, Y. M. Chae, M. I. Ham, K. J. Lee, H. J. Kwon, and K. M. Ahn, Analysis of Regional Prevalence of Allergic Diseases in Korean School Children. Allergy Asthma \& Respiratory Disease. 3, 1, (2015)

[8] Korea Centers for Disease Control and Prevention, The Sixth Korea National Health and Nutrition Examination Survey (KNHANES VI-1). (2013)

[9] https://www.cdc.gov/exposurereport, Jan 29 (2017).

[10] C. Schulz, M. Wilhelm, U. Heudorf, and M. Kolossa-Gehring, Reprint of Update of the Reference and HBM Values Derived by the German Human Biomonitoring Commission. International Journal of Hygiene and Environmental Health. 215, 2, (2012) 
[11] https://www.canada.ca/en/health-canada/services/environmental-workplace-health/reportspublications/environmental-contaminants/table-10-blood-lead-levels-blls-canada-united-states-canadianadults-children.html, Jan 11 (2013). 